\title{
Effects of Intrauterine Environment on the Magnitude of Differences Within the Pairs of Monozygotic and Dizygotic Twins
}

\author{
Małgorzata Waszak, ${ }^{1}$ Krystyna Cieślik, ${ }^{1}$ Marzena Skrzypczak-Zielińska, ${ }^{2}$ Marlena Szalata, ${ }^{2}$ \\ Karolina Wielgus, ${ }^{3}$ Oliwia Zakerska-Banaszak, ${ }^{2}$ Grzegorz Bręborowicz, ${ }^{4}$ and Ryszard Słomski ${ }^{2}$ \\ ${ }^{1}$ Department of Functional Anatomy, University School of Physical Education, Poznan, Poland \\ ${ }^{2}$ Institute of Human Genetics, Polish Academy of Sciences, Poznan, Poland \\ ${ }^{3}$ Department of Biotechnology and Molecular Biology, Institute of Natural Fibres and Medicinal Plants, Poznan, Poland \\ ${ }^{4}$ Department of Perinatology and Gynaecology, University of Medical Sciences, Poznan, Poland
}

\begin{abstract}
The aim of this study was to determine the effects of intrauterine environment on the magnitude of intrapair differences in six somatic traits of monozygotic (MZ) and dizygotic (DZ) twins (1,263 pairs; $424 \mathrm{MZ}$ twins and $839 \mathrm{DZ}$ twins). Differences in intrauterine environments of $\mathrm{MZ}$ twins enforced division of the research material into four groups: (1) MZ-MC-TTTS - MZ twins from monochorionic (MC) pregnancies with twin-to-twin transfusion syndrome (TTTS), (2) MZ-MC (without TTTS) - MZ twins from MC pregnancies without TTTS, (3) MZ-DC-MZ twins from dichorionic (DC) pregnancies, and (4) DZ-DZ twins. The intrapair differences in all analyzed somatic traits, especially body weight and circumference of the chest, were the largest in the case of $\mathrm{MZ}$ twins from MC pregnancies with TTTS. DZ twins were the group presenting with the second largest intrapair differences in the analyzed traits. At the end of pregnancy, that is, in lunar months 9 and 10, the magnitude of intrapair differences in all traits of twins from this group was significantly greater than in $M Z$ twins from both MC and DC pregnancies. Irrespective of the analyzed period, the least evident, statistically insignificant intrapair differences in the studied traits were documented in the case of $M Z$ twins from $M C$ pregnancies without TTTS and twins from DC pregnancies. These findings imply that the differentiating effect of intrauterine environment is associated with the occurrence of TTTS, rather than with chorionicity, as postulated previously.
\end{abstract}

Keywords: twin-to-twin transfusion syndrome, monochorionic placenta, dichorionic placenta, chorion in multiple pregnancies

The contribution of genetic and environmental factors to phenotypic variance observed during the perinatal period can be estimated on the basis of differences within the pairs of twins. This type of research, the so-called twin studies, is based on the assumption that monozygotic (MZ) twins are genetically identical and dizygotic (DZ) twins are related to the same degree as any other siblings. Appropriate use of this method requires not only information on zygosity type but most of all on chorionicity, as these two parameters are vital for determining the effects of intrauterine environment on twin development. However, a question arises whether the intrauterine environment can be considered homogeneous for all twins?

According to some researchers, the intrauterine environment can be considered similar only in the case of DZ twins and MZ twins from dichorionic (DC) and diamniotic pregnancies, as only these fetuses develop in separate chorions and amnions (Bergman \& Sawicki, 1988; Gielen et al., 2008; Loos et al., 2005, Touwslager et al., 2011; Vlietinck et al., 1989; van Baal \& Boomsma, 1998). In turn, fetuses from monochorionic (MC) - either di- or monoamniotic - pregnancies develop under different intrauterine conditions and therefore are at risk of many complications (Baldwin, 1994; Benirschke, 1990; Cordero et al., 2005, 2006; De Paepe, 2015; Dias et al., 2010; Hack et al., 2008; Haverkamp et al., 2001; Rossi \& Prefumo, 2013;

RECEIVED 20 June 2016; ACCEPTED 12 October 2016. First published online 1 December 2016.

ADDRESS FOR CORRESPONDENCE: Dr. Małgorzata Waszak, Department of Functional Anatomy, University School of Physical Education, 27/39 Królowej Jadwigi Str., 61-871 Poznan, Poland. E-mail: malwasz@interia.pl 
Zhao et al., 2016). The most common complication is the formation of connecting blood vessels (anastomoses), which may result in acute or chronic twin-to-twin transfusion syndrome (TTTS).

Placental anastomoses observed during the course of TTTS (also referred to as feto-fetal transfusion syndrome) allow blood to pass from one fetus (the so-called donor) to the other (the so-called recipient). Resultant hemodynamic imbalance leads to various abnormalities (Bermudez et al., 2002; Lewi, 2010; Ropacka et al., 2001; Zanardini et al., 2014; Zhao et al., 2016), such as hypertension, polycythemia, and hypervolemia in the recipient, and hypotonia, hypovolemia, and anemia in the donor (Malinowski \& Ropacka, 2003; Yinon et al., 2014; Zhao et al., 2014). Moreover, TTTS is reflected by enhanced growth of the recipient and delayed development of the donor, which eventually results in growth discordance (Fick et al., 2006). Discordant growth, manifesting as differences in fetal body weights and abdominal circumferences, is a characteristic feature of TTTS.

Previous studies showed that intrapair differences in $\mathrm{MZ}$ twins result solely from the influence of unique intrauterine factors (Race et al., 2006; Sokol et al., 1995). This may either promote growth discordance (e.g., in the case of TTTS, according to Ropacka, 2003, observed in up to $15-20 \%$ of MC twins) or prevent it, if transfer of blood between co-twins is not associated with TTTS. TTTS may result in considerable birth-weight discordance (Blickstein, 1990; Brennan et al., 1982; Fick et al., 2006; Foley et al., 2000). Formation of anastomoses between vascular systems of DZ twins with fused placentas is of extremely rare evidence (ca. 1.4\%; Lage et al., 1989; Robertson \& Neer, 1983) and leads to blood chimerism (Baldwin, 1994; Malinowski \& Ropacka, 2003). Consequently, it is still unclear whether shared chorion and placenta present in most MZ twins (70\%) provide them with more similar environmental conditions than in the case of DZ twins, which always develop in separate chorions, and according to Bulmer (1970), have separate placentas in $58 \%$ of the cases.

The aim of this study was to determine the effects of intrauterine environment on the magnitude of intrapair differences in the somatic traits of MZ and DZ twins.

We verified previous opinions regarding conditions of twin intrauterine development, comparing the degree of intrapair discordance of somatic traits in $\mathrm{MZ}$ and DZ twins presenting with different types of fetal membranes. Only a few comparisons of this kind have been carried out, using sufficiently numerous and clinically selected twin material, and there remains a lack of reliable opinions on the subject (Silventoinen et al., 2015). The lack of such analyses reflects difficulties in access to sufficiently large research material, of which a principal limiting factor is the relatively low rate of twin births. In Poland, twin pregnancy occurs once per 80 births. MZ twins represent $30 \%$ of all delivered twins, and only $30 \%$ of MZ twins develop in separate chorions and amnions.

Consequently, this study involving sufficiently large and representative material may provide an evidence for such conclusions.

In pursuing the goal of our research, we aimed to prove the veracity of the following research hypotheses:

1. The number of chorions in twin pregnancies is not a significant factor influencing the size of intrapair differences in the somatic traits in twins. TTTS can be considered such a factor.

2. Material on DZ and MZ twins from MC or DC pregnancies but without TTTS ensures comparability of intrauterine environmental conditions and can be used to estimate the share of genetic and environmental factors in the variability of phenotypic traits in the perinatal period.

\section{Methods}

The studied material, including 1,263 pairs of twins liveborn at various stages of fetal life between the 22nd and 41 st week of gestation, was collected from the Department of Perinatology and Gynaecology, Poznan University of Medical Sciences, between 2003 and 2012. Individuals with clinical evidence of congenital anomalies or mechanical injuries, as well as neonates whose data were likely unreliable, were excluded from further analyses.

The calendar age of the neonates was determined on the basis of maternal information on the first day of the last menstrual period. The number of male and female neonates born in consecutive weeks of gestation and numbers of twin pairs from consecutive lunar months is presented in Table 1.

The general status of each neonate was determined immediately after birth and expressed as an Apgar score, being a complex functional measure of the respiratory, cardiovascular, and central nervous systems. Apgar scores were interpreted according to widely accepted criteria: $10-8$ pointsnormal, 7.5-6 points-intermediate, 5.5-4 points-fairly low, and 3.5-0 points-critically low. The study included only the twins whose general status at birth corresponded to an Apgar score $>4$ points. Stillborn neonates were excluded from the analysis.

Morphological development of each twin was assessed on the basis of six somatic traits: (1) body weight, (2) total body length, (3) crown-rump length, (4) shoulder width, (5) circumference of the head, and (6) circumference of the chest. Definitions of all these traits and methods of their measurement were consistent with conventional methodology proposed by Martin (1988).

The chorionicity was described in the first half of the pregnancy by ultrasound scan and in some cases also immediately after the birth based on the analysis of the placenta. 
TABLE 1

Number of Male and Female Newborns from Twin Pregnancies Born at Various Gestational Weeks (22-41) and the Number of Twin Pairs Born in Various Lunar Months

\begin{tabular}{|c|c|c|c|c|c|c|c|c|c|c|c|c|c|c|c|c|c|c|c|c|}
\hline Lunar month & 6 & & & & 7 & & & & 8 & & & & 9 & & & & 10 & & & \\
\hline Week & 22 & 23 & 24 & 25 & 26 & 27 & 28 & 29 & 30 & 31 & 32 & 33 & 34 & 35 & 36 & 37 & 38 & 39 & 40 & 41 \\
\hline$\hat{0}$ & 3 & 7 & 9 & 13 & 23 & 20 & 16 & 22 & 22 & 46 & 69 & 61 & 109 & 131 & 206 & 294 & 144 & 63 & 19 & 5 \\
\hline 우 & 3 & 3 & 3 & 5 & 23 & 16 & 14 & 32 & 36 & 42 & 47 & 65 & 85 & 159 & 216 & 276 & 128 & 67 & 15 & 9 \\
\hline Twin pairs & 14 & & & & 65 & & & & 158 & & & & 516 & & & & 510 & & & \\
\hline
\end{tabular}

The zygosity of 821 pairs of same-gender twins was determined at the Laboratory of Molecular Genetics in Poznan. Biological material was $1 \mathrm{~mL}$ of umbilical blood collected in EDTA tubes $(10 \mathrm{~mL}$ of $10 \%$ EDTA per $1 \mathrm{~mL}$ of the blood). The material was obtained immediately after birth to avoid exposure of twins to additional medical procedures. This is particularly important in the case of multiple pregnancies, which usually result in more complicated labor, lower birth weights, and worse physical condition of neonates than singleton pregnancies. Special attention was paid to material collection, appropriate labeling of each sample, storage, and isolation of DNA with the aid of techniques providing high throughput of the process and high degree of DNA purity. DNA was always isolated from lysate of umbilical blood lymphocytes, and purified by salting out of proteins. Such processed material was subjected to analysis of DNA polymorphism by means of hybridization with a molecular probe and with an aid of PCR. The hybridization studies included analysis of single locus systems (SLS): D7S21 (7p22) and D12S11 (12q24.3) with MS43A and MS31 probes, and simultaneous analysis of multi-locus systems (MLSs) with a (GTG) 5 probe. PCR was used to analyze short tandem repeat (STR) polymorphisms within the following genes: pancreatic phospholipase (HUMPLA2A1, 12q23), cytochrome P450 (HUMCYARO, 15q21.1), von Willebrand factor (HUMvWF, 12p13), thyroid peroxidase (HUMTPOX, 2p23), and tyrosine hydroxylase (HUMTH01, 11p15.5). The analysis included loci located on five different chromosomes.

All the procedures were approved by the Local Ethics Committee of the Medical University in Poznan.

The study used the following methods of mathematical statistics:

1. Student's $t$ test to determine the significance of differences between the two variables;

2. Fisher's test to verify the homogeneity of variance;

3. one-dimension and two-factor analysis of ANOVA variance for somatic traits in twins, standardized by gender and gestational age in order to reveal the diversity of the dependent variables, distinguished between the chosen categories of twins;

4. post-hoc test to determine the categories between which twins differences for variable data were statistically significant;

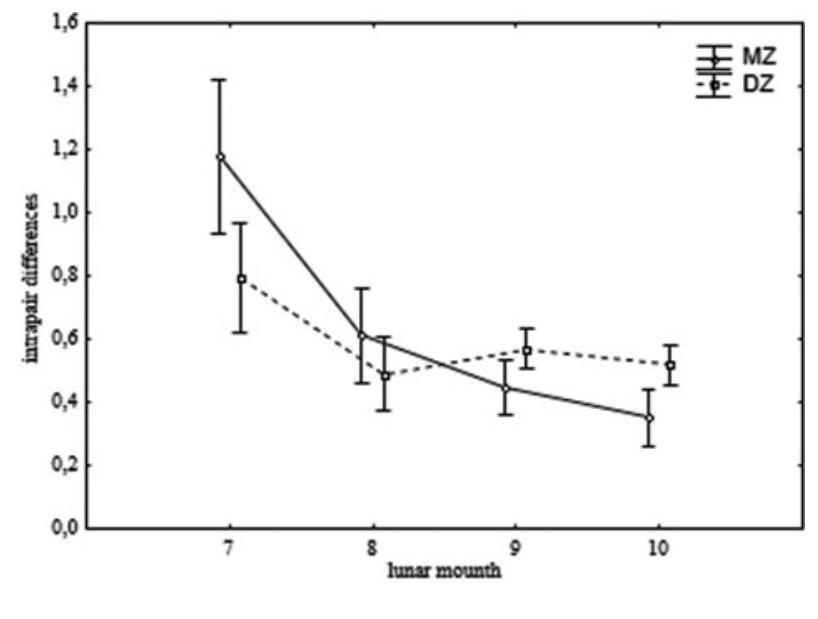

\section{FIGURE 1}

Intrapair differences in the standardized body weight of $M Z$ and DZ twins from consecutive lunar months. Vertical bars represent $95 \%$ confidence intervals for a mean.

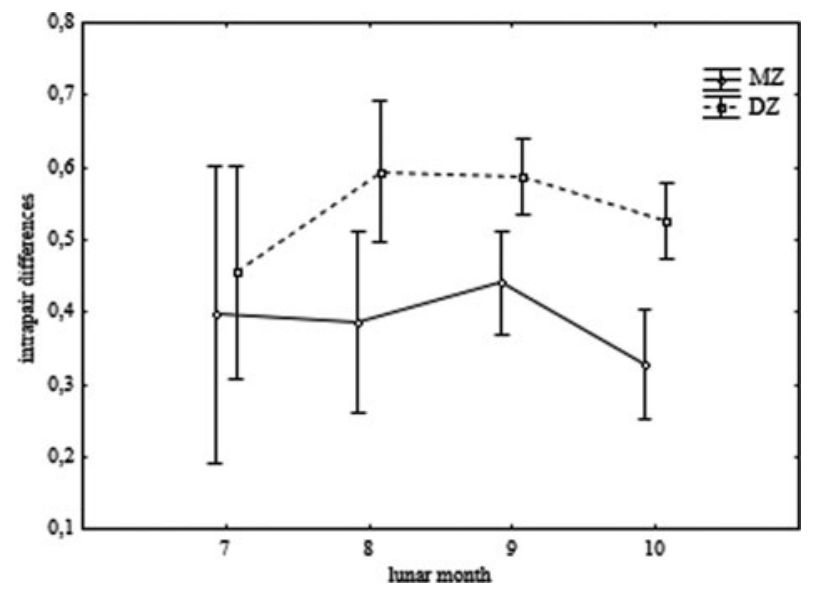

FIGURE 2

Intrapair differences in the standardized total body length of $M Z$ and $D Z$ twins from consecutive lunar months. Vertical bars represent $95 \%$ confidence intervals for a mean.

5. a graphic interpretation of the obtained results was also performed in the form of the graphs shown in Figures 1-10. The 95\% confidence interval for the mean defines the range of values around the mean, which with $95 \%$ probability contains the true value of the mean. The size of the confidence interval depends 


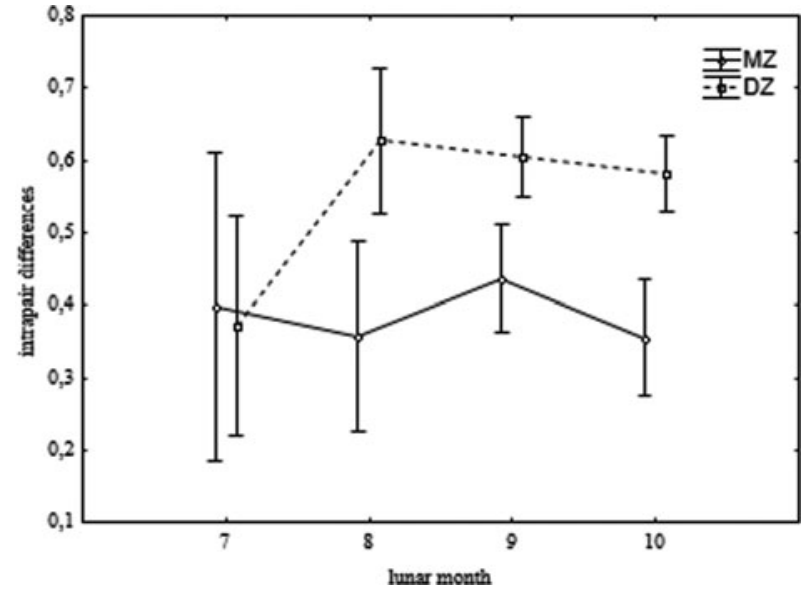

\section{FIGURE 3}

Intrapair differences in the standardized crown-rump length of $M Z$ and $D Z$ twins from consecutive lunar months. Vertical bars represent $95 \%$ confidence intervals for a mean.

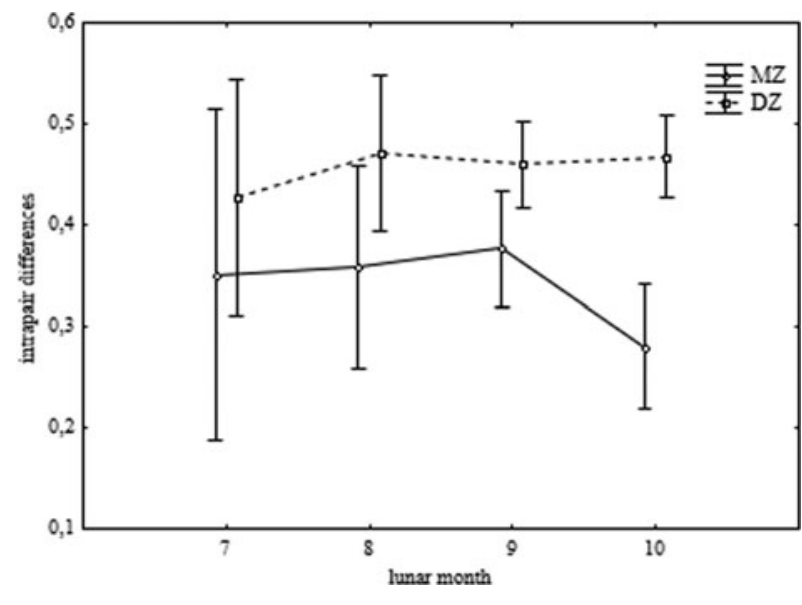

\section{FIGURE 4}

Intrapair differences in the standardized head circumference of $M Z$ and $D Z$ twins from consecutive lunar months. Vertical bars represent $95 \%$ confidence intervals for a mean.

on the sample size and variability of the given characteristic. An increase in the number of observations and less data dispersion causes narrowing of the confidence interval. When confidence intervals for the two means do not overlap, it means that they differ significantly.

\section{Results}

During the first stage of the intrapair discordance analysis, we conducted a Student $t$ test to compare the magnitude of intrapair differences in each of the analyzed somatic traits of $\mathrm{MZ}$ and $\mathrm{DZ}$ twins. The test showed that $\mathrm{MZ}$ and $\mathrm{DZ}$ twins differed significantly in the magnitude of intrapair differences in all analyzed traits except for body weight (Table 2).

The Fisher test did not provide any evidence to reject the hypothesis on the homogeneity of variance in all ana-

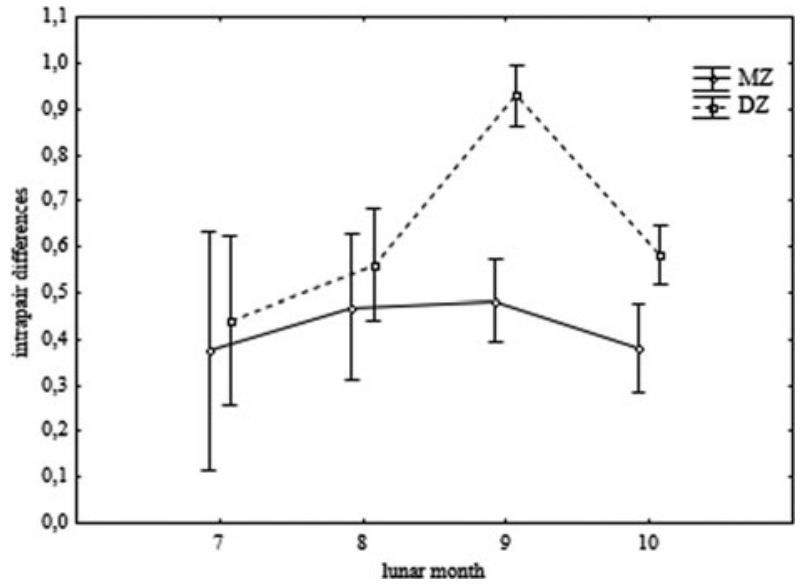

FIGURE 5

Intrapair differences in the standardized chest circumference of $M Z$ and $D Z$ twins from consecutive lunar months. Vertical bars represent $95 \%$ confidence intervals for a mean.

lyzed traits of $\mathrm{MZ}$ and $\mathrm{DZ}$ twins except for body weight. The value of the standard deviation for body weight of MZ twins, pointing to a considerable heterogeneity of intrapair differences in this parameter, was significantly higher than in the case of $\mathrm{DZ}$ twins ( $p$ value for $F$ statistic was lower than 0.01 and therefore the criterion of variance homogeneity was not satisfied). This substantiated the use of the unequal variance in the Student $t$ test. This test did not provide any evidence $(p=.06)$ to reject the hypothesis on the homogeneity of the two groups of $\mathrm{MZ}$ and $\mathrm{DZ}$ twins. Therefore, $M Z$ twins did not differ significantly from $D Z$ twins in terms of their mean intrapair differences in body weight.

Moreover, we analyzed the magnitude of intrapair differences in the somatic traits of MZ and DZ twins from consecutive lunar months. Classification according to a lunar month was enforced by a small number $(n<20)$ of twins from some weeks of gestation. The results of the analysis are depicted in Figures 1-5.

As shown in the figures, during the whole prenatal period, intrapair discordance in all analyzed somatic traits except for body weight was larger in DZ twins than in MZ twins, but this difference was statistically significant only for terminal period of fetal ontogenesis, that is, for lunar months 9 and 10. In turn, the differences in the magnitude of intrapair discordance in body weight, apparently larger in MZ twins for lunar months 7 and 8, and in DZ twins for lunar months 9 and 10 , were not statistically significant during the whole fetal ontogenesis.

We conducted a univariate two-way analysis of variance (ANOVA) to study the effects of zygosity and fetal age on the magnitude of intrapair differences in the somatic traits of twins (Table 3). The $p$ values for univariate tests suggested that zygosity exerted no significant effect on body weight, and fetal age did not modulate significantly either crown-rump length or circumference of the 


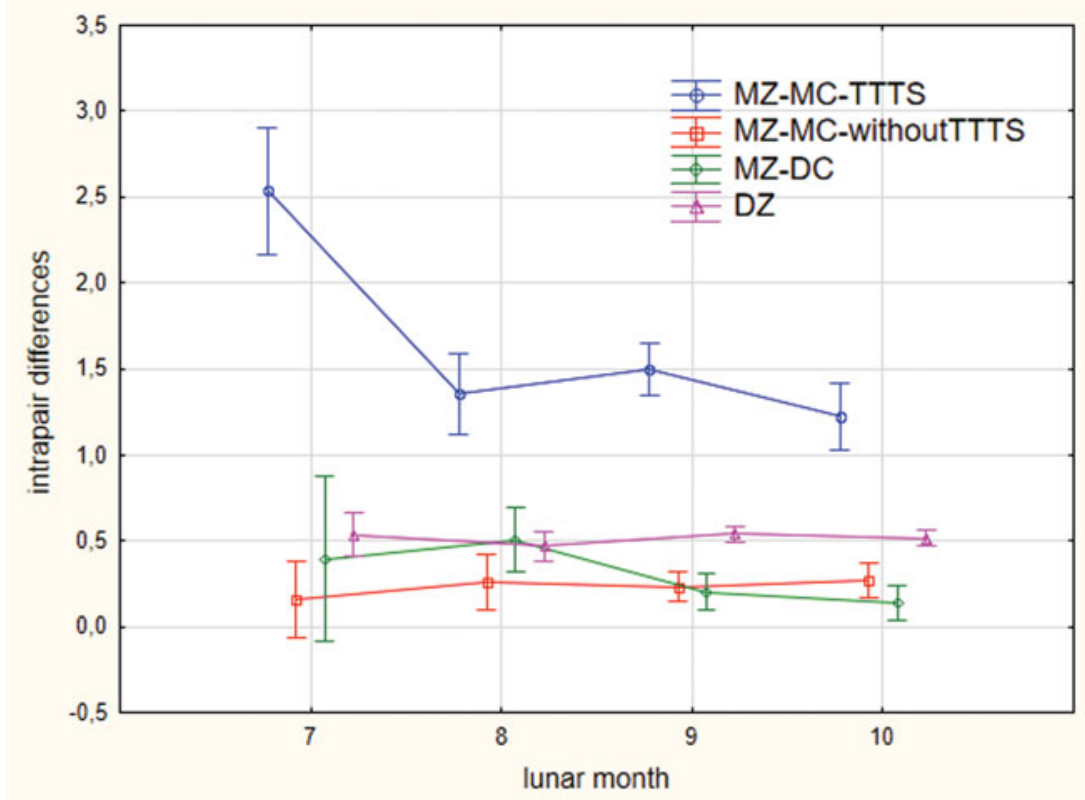

\section{FIGURE 6}

(Colour online) Intrapair differences in the standardized body weight for four groups of twins from consecutive lunar months, stratified according to their zygosity and chorionicity. Vertical bars represent $95 \%$ confidence intervals for a mean.

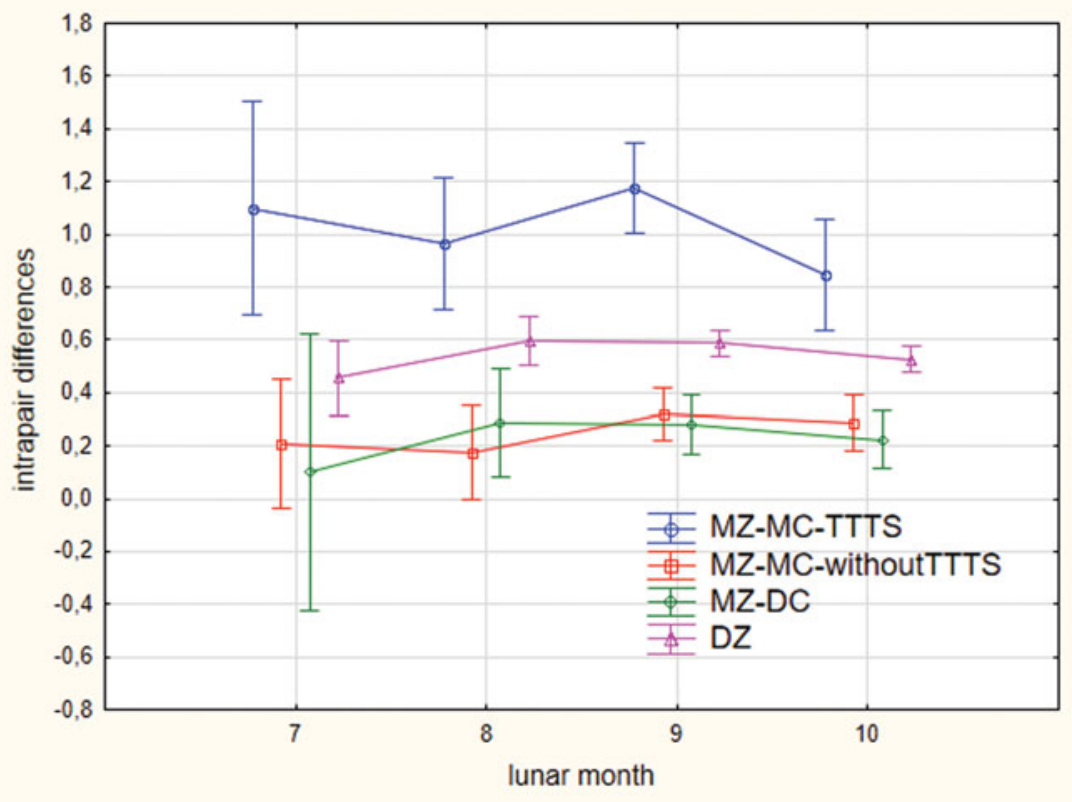

FIGURE 7

(Colour online) Intrapair differences in the standardized total body length for four groups of twins from consecutive lunar months, stratified according to their zygosity and chorionicity. Vertical bars represent $95 \%$ confidence intervals for a mean.

head. In contrast, both these factors exerted significant effects on total body length and circumference of the chest. In the case of the latter parameter, however, their effects were non-additive, that is, did not sum, and were additionally modulated due to interaction between the analyzed factors.
$Y$ is a somatic trait influenced by factors $\alpha$ and $\beta$ :

$Y=\mu+\alpha+\beta+(\alpha \beta)+e$

where $\mu$ : global mean value;

$\alpha$ : effect of zygosity factor;

$\beta$ : effect of fetal age factor; 


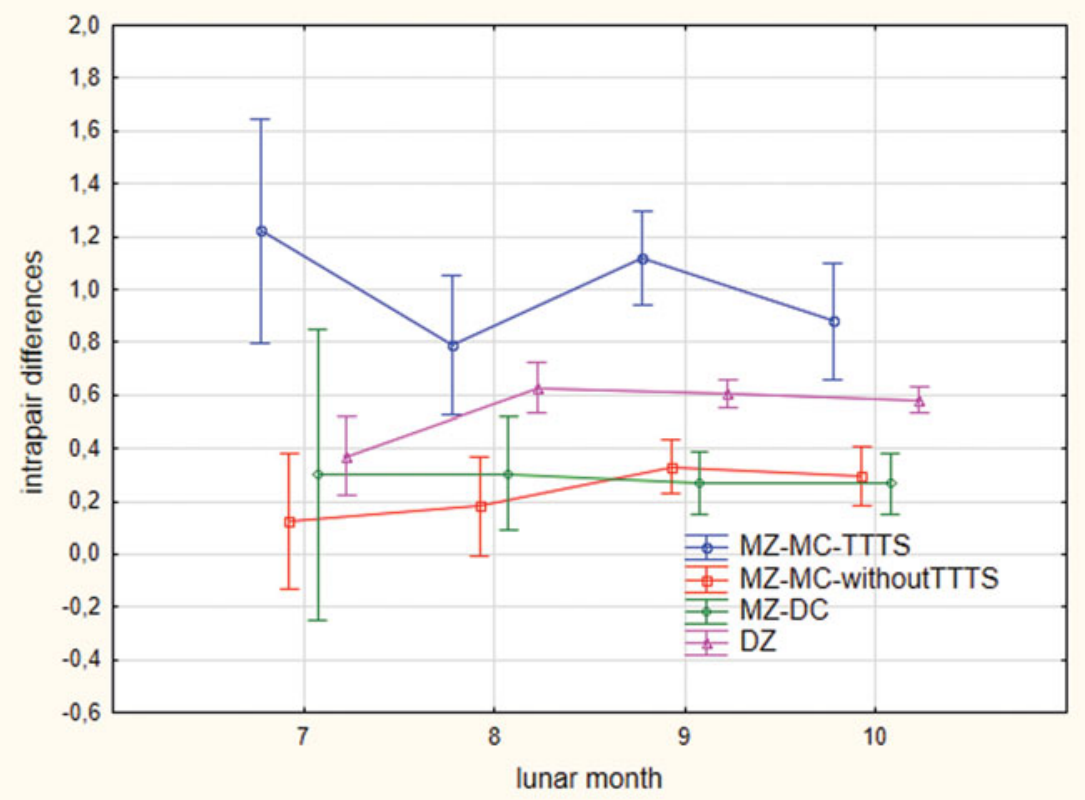

\section{FIGURE 8}

(Colour online) Intrapair differences in the standardized crown-rump length for four groups of twins from consecutive lunar months, stratified according to their zygosity and chorionicity. Vertical bars represent $95 \%$ confidence intervals for a mean.

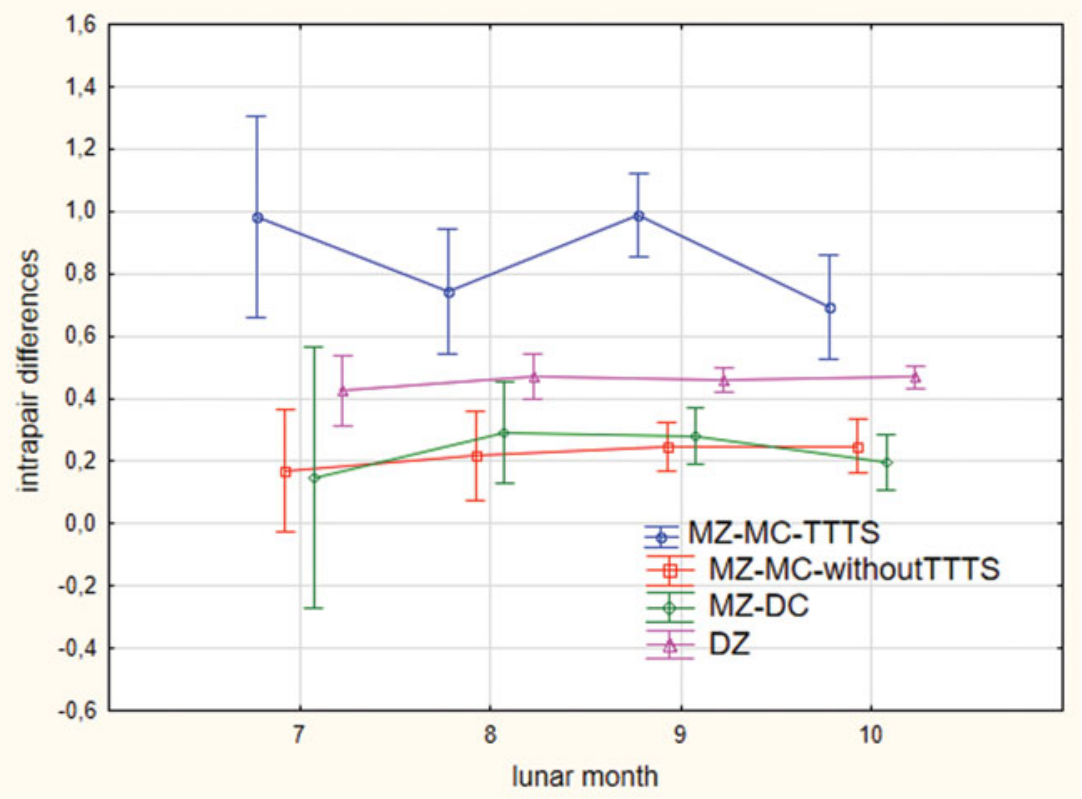

\section{FIGURE 9}

(Colour online) Intrapair differences in the standardized head circumference for four groups of twins from consecutive lunar months, stratified according to their zygosity and chorionicity. Vertical bars represent $95 \%$ confidence intervals for a mean.

$\alpha \beta$ : effect of interaction, i.e., zygosity $\times$ fetal age; and e: error.

MZ twins may develop under different intrauterine environmental conditions, which to some extent depends on the time elapsed between fertilization and division of a single zygote into two genetically identical embryonic structures. Such twins may develop within two separate chorions or share the same chorion.

Potential discordance in the intrauterine environments of MZ twins enforced stratification of our research material into four groups: (1) MZ-MC-TTTS-MZ twins from MC pregnancy with TTTS, (2) MZ-MC-MZ twins 


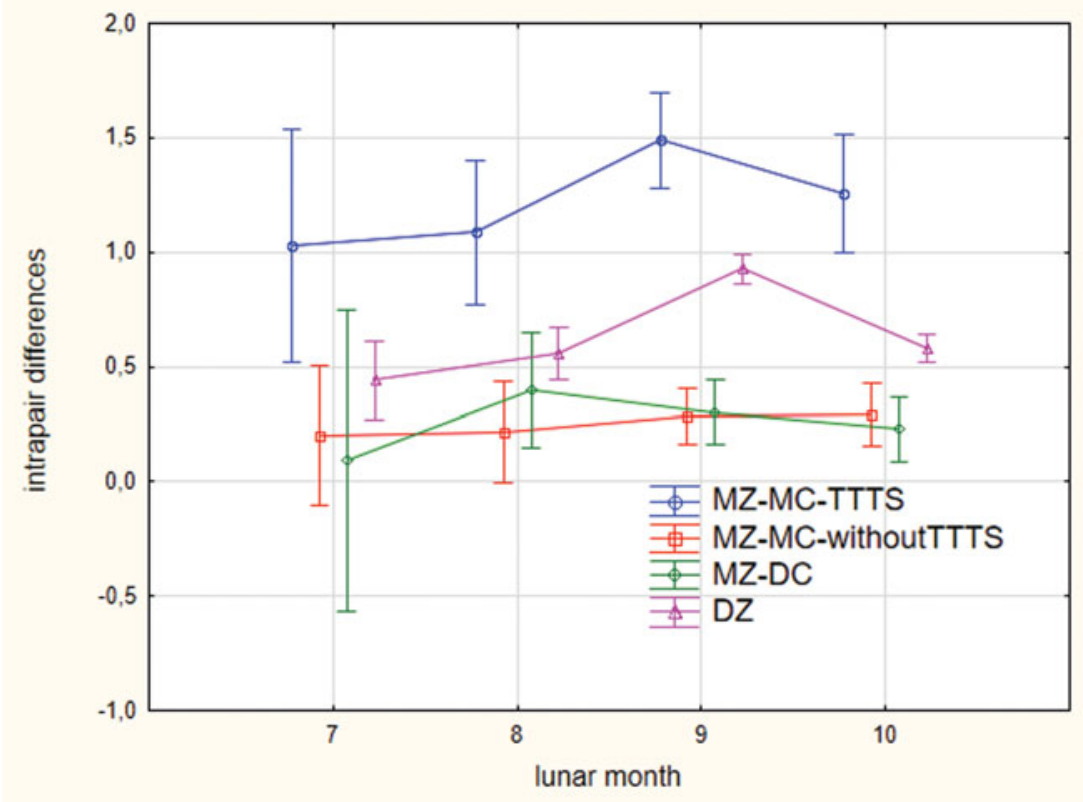

\section{FIGURE 10}

(Colour online) Intrapair differences in the standardized chest circumference for four groups of twins from consecutive lunar months, stratified according to their zygosity and chorionicity. Vertical bars represent $95 \%$ confidence intervals for a mean.

TABLE 2

Results of Student $t$ Test Conducted to Compare Mean Magnitude of Intrapair Differences in the Standardized Somatic Traits of Monozygotic and Dizygotic Twins

\begin{tabular}{|c|c|c|c|c|c|c|c|c|}
\hline \multirow[b]{2}{*}{ Trait } & \multicolumn{3}{|c|}{ MZ twins } & \multicolumn{3}{|c|}{ DZ twins } & \multirow[b]{2}{*}{$t$} & \multirow[b]{2}{*}{$p$} \\
\hline & $x$ & $N$ & $S D$ & $x$ & $N$ & $S D$ & & \\
\hline Body weight & 0.47 & 420 & 0.78 & 0.55 & 827 & 0.48 & -1.85 & .0591 \\
\hline Total body length & 0.39 & 420 & 0.49 & 0.56 & 827 & 0.49 & -5.66 & .0012 \\
\hline Crown-rump length & 0.39 & 419 & 0.48 & 0.59 & 825 & 0.52 & -6.28 & .0005 \\
\hline Head circumference & 0.34 & 420 & 0.39 & 0.46 & 827 & 0.39 & -5.37 & .0023 \\
\hline Chest circumference & 0.44 & 420 & 0.61 & 0.71 & 827 & 0.65 & -7.24 & .0000 \\
\hline
\end{tabular}

Note: $p$ values are significant at $p \leq .05$.

\section{TABLE 3}

Results of Univariate Two-Way Analysis of Variance (ANOVA) for Intrapair Differences in Standardized Somatic Traits

\begin{tabular}{|c|c|c|c|c|c|}
\hline \multirow[b]{2}{*}{ Effect } & \multicolumn{5}{|c|}{ Univariate significance tests for intrapair differences in somatic traits $p$ values } \\
\hline & Body weight & Total body length & Crown-rump length & Head circumference & Chest circumference \\
\hline Zygosity & .26682 & .00023 & .00021 & .00051 & .00011 \\
\hline Fetal age (lunar months) & .00000 & .04823 & .17366 & .36503 & .00000 \\
\hline Interaction: zygosity $\times$ fetal age & .00089 & .65996 & .22944 & .22974 & .00150 \\
\hline
\end{tabular}

from MC pregnancy without TTTS, (3) MZ-DC-MZ twins from DC pregnancy, and (4) DZ twins. These groups were compared in terms of the magnitude of intrapair differences in the standardized somatic traits (Table 4).

MZ twins from MC pregnancies with TTTS were characterized by the largest intrapair differences in all analyzed traits, especially body weight and circumference of the chest (Table 4).
Analysis of variance, the results of which are presented in Table 5, confirmed that intrauterine environmental conditions exerted significant effects on the magnitude of intrapair differences in the analyzed traits. The least significant difference (LSD) test identified the groups of twins that differed significantly in terms of the magnitude of intrapair differences. MZ twins from MC pregnancies without TTTS and MZ twins from DC pregnancies turned out to be the only groups that did not differ significantly in terms of 


\section{TABLE 4}

Descriptive Statistics for Absolute Magnitude of Intrapair Differences in the Standardized Somatic Traits of Twins Stratified According to Their Zygosity and Chorionicity

\begin{tabular}{|c|c|c|c|c|c|c|c|c|c|c|c|}
\hline \multirow[b]{2}{*}{ Group } & \multirow[b]{2}{*}{$N$} & \multicolumn{2}{|c|}{ Body weight } & \multicolumn{2}{|c|}{ Total body length } & \multicolumn{2}{|c|}{ Crown-rump length } & \multicolumn{2}{|c|}{ Head circumference } & \multicolumn{2}{|c|}{ Chest circumference } \\
\hline & & $x$ & $S D$ & $x$ & $S D$ & $x$ & $S D$ & $x$ & $S D$ & $x$ & $S D$ \\
\hline 1 & 66 & 1.65 & 1.17 & 1.03 & 0.73 & 0.99 & 0.77 & 0.85 & 0.62 & 1.31 & 0.98 \\
\hline 2 & 199 & 0.26 & 0.24 & 0.28 & 0.32 & 0.28 & 0.29 & 0.24 & 0.24 & 0.27 & 0.29 \\
\hline 3 & 155 & 0.25 & 0.54 & 0.25 & 0.28 & 0.27 & 0.29 & 0.24 & 0.22 & 0.28 & 0.31 \\
\hline 4 & 827 & 0.55 & 0.48 & 0.56 & 0.49 & 0.59 & 0.52 & 0.46 & 0.39 & 0.71 & 0.65 \\
\hline
\end{tabular}

Note: Group 1 = MZ-MC-TTTS, Group 2 = MZ-MC without TTTS, Group 3 = MZ-DC, and Group 4 = DZ.

\section{TABLE 5}

Results of the Analysis of Variance for a Relationship Between 'Twin Category According to Zygosity and Chorionicity' Factor and Selected Dependent Variables (Absolute Magnitude of Intrapair Differences in Standardized Somatic Traits)

\begin{tabular}{lllll}
\hline Dependent variables & $F$ & $d f_{1}$ & $d f_{2}$ & $p$ \\
\hline Body weight & 136.64 & 3 & 1243 & .00000 \\
Total body length & 62.30 & 3 & 1243 & .00431 \\
Crown-rump length & 54.09 & 3 & 1240 & .00356 \\
Head circumference & 62.03 & 3 & 1243 & .00021 \\
Chest circumference & 75.63 & 3 & 1243 & .00004 \\
\hline
\end{tabular}

Note: $p$ values are significant at $p \leq .05$.

\section{TABLE 6}

Significance of Differences in the Magnitude of Intrapair Discordance in Standardized Somatic Traits in the Subsets of Twins Differing in Terms of Their Zygosity and Chorionicity

\begin{tabular}{lllll}
\hline Body weight & MZ-MC-TTTS & MZ-MC & MZ-DC & DZ \\
\hline MZ-MC-TTTS & & $* *$ & $* *$ & $* *$ \\
MZ-MC & $* *$ & & - & $* *$ \\
MZ-DC & $* *$ & - & & $* *$ \\
DZ & $* *$ & $* *$ & $* *$ & \\
Total body length & MZ-MC-TTTS & MZ-MC & MZ-DC & DZ \\
MZ-MC-TTTS & & $* *$ & $* *$ & $* *$ \\
MZ-MC & $* *$ & & - & $* *$ \\
MZ-DC & $* *$ & - & & $* *$ \\
DZ & $* *$ & $* *$ & $* *$ & \\
Crown-rump length & MZ-MC-TTTS & MZ-MC & MZ-DC & DZ \\
MZ-MC-TTTS & & $* *$ & $* *$ & $* *$ \\
MZ-MC & $* *$ & & - & $* *$ \\
MZ-DC & $* *$ & - & & $* *$ \\
DZ & $* *$ & $* *$ & $* *$ & \\
Head circumference & MZ-MC-TTTS & MZ-MC & MZ-DC & DZ \\
MZ-MC-TTTS & & $* *$ & $* *$ & $* *$ \\
MZ-MC & $* *$ & & - & $* *$ \\
MZ-DC & $* *$ & - & & $* *$ \\
DZ & $* *$ & $* *$ & $* *$ & \\
Chest circumference & MZ-MC-TTTS & MZ-MC & MZ-DC & DZ \\
MZ-MC-TTTS & & $* *$ & $* *$ & $* *$ \\
MZ-MC & $* *$ & - & - & $* *$ \\
MZ-DC & $* *$ & $* *$ & $* *$ & $* *$ \\
DZ & $* *$ & & & \\
\hline Note: & & - & & \\
\hline
\end{tabular}

Note: ${ }^{\star *}$ significant at $p \leq .01$.

the magnitude of intrapair differences in the analyzed traits (Table 6).

To determine the effects of intrauterine environment and fetal age in lunar months on the magnitude of intrapair differences, we conducted a univariate two-way ANOVA. The analysis showed that both the abovementioned factors exerted significant effects on body weight and circum- ference of the chest. These non-additive effects were additionally modulated by an interaction between the two factors. The magnitude of intrapair differences in the remaining traits was modulated solely by intrauterine environment (Table 7).

Moreover, we analyzed the effects on intrauterine environmental conditions on the magnitude of intrapair differences in the studied somatic traits in consecutive lunar months. The results of this analysis are depicted in Figures 6-10.

As shown in the figures, irrespective of the analyzed trait, the intrapair differences were the largest in the case of $\mathrm{MZ}$ twins from MC pregnancies with TTTS. The twins from this subset differed significantly from the remaining groups for nearly the whole period of fetal ontogenesis. DZ twins were the group presenting with the second largest intrapair differences in the analyzed traits. At the end of pregnancy, that is, in lunar months 9 and 10, the magnitude of intrapair differences in all traits of twins from this group was significantly greater than in $\mathrm{MZ}$ twins from both $\mathrm{MC}$ and DC pregnancies. Irrespective of the analyzed period, the least evident, statistically insignificant intrapair differences in the studied traits were documented in the case of $\mathrm{MZ}$ twins from MC pregnancies without TTTS and twins from DC pregnancies.

The results of previous studies of fetal membrane biology imply that MZ twins and DZ twins developing within separate chorions and amnions are the only groups being comparable in terms of their intrauterine environments (Bergman \& Sawicki, 1988; Loos et al., 2005; van Baal \& Boomsma, 1998). The only difference in the intrauterine environments of these twins may pertain to the number of placentas, as they may either develop in two separate placentas or share a common placenta. To verify whether this factor influenced the magnitude of intrapair differences in somatic traits, we compared the subsets of $M Z$ twins from DC pregnancies and DZ twins differing in terms of the placental numbers (Table 8).

Analysis of variance revealed statistically significant differences $(p \leq .01)$ in the magnitude of intrapair discordance in the analyzed traits of twins from various subsets (Table 9), and the LSD test documented relationships between specific subgroups of twins. The only significant differences were observed between group 1 and groups 3 and 
TABLE 7

Results of Univariate Two-Way Analysis of Variance (ANOVA) for Intrapair Differences in Standardized Somatic Traits

\begin{tabular}{|c|c|c|c|c|c|}
\hline \multirow[b]{2}{*}{ Effect } & \multicolumn{5}{|c|}{ Univariate significance tests for intrapair differences in somatic traits $p$ values } \\
\hline & Body weight & Total body length & Crown-rump length & Head circumference & Chest circumference \\
\hline Fetal age (lunar months) & .00000 & .04594 & .21355 & .07343 & .00194 \\
\hline Four groups\# & .00000 & .00000 & .00000 & .00000 & .00000 \\
\hline Interaction: fetal age $\times$ four groups & .00000 & .61535 & .26582 & .25705 & .00697 \\
\hline
\end{tabular}

Note: \#According to zygosity and chorionicity.

TABLE 8

Descriptive Statistics for Absolute Magnitude of Intrapair Differences in the Standardized Somatic Traits of Twins Stratified According to Their Zygosity and Number of Placentas

\begin{tabular}{|c|c|c|c|c|c|c|c|c|c|c|c|}
\hline \multirow[b]{2}{*}{ Group } & \multirow[b]{2}{*}{$N$} & \multicolumn{2}{|c|}{ Body weight } & \multicolumn{2}{|c|}{ Total body length } & \multicolumn{2}{|c|}{ Crown-rump length } & \multicolumn{2}{|c|}{$\begin{array}{l}\text { Head } \\
\text { circumference }\end{array}$} & \multicolumn{2}{|c|}{ Chest circumference } \\
\hline & & $x$ & $S D$ & $x$ & $S D$ & $x$ & $S D$ & $x$ & $S D$ & $x$ & $S D$ \\
\hline MZ DC 1p & 90 & 0.26 & 0.55 & 0.27 & 0.28 & 0.29 & 0.30 & 0.25 & 0.24 & 0.29 & 0.31 \\
\hline MZ DC 2p & 65 & 0.22 & 0.52 & 0.22 & 0.27 & 0.26 & 0.29 & 0.23 & 0.19 & 0.27 & 0.30 \\
\hline DZ 1p & 440 & 0.51 & 0.43 & 0.55 & 0.49 & 0.57 & 0.53 & 0.44 & 0.39 & 0.69 & 0.61 \\
\hline$D Z 2 p$ & 389 & 0.53 & 0.43 & 0.56 & 0.50 & 0.60 & 0.52 & 0.49 & 0.39 & 0.74 & 0.68 \\
\hline
\end{tabular}

\section{TABLE 9}

Results of the Analysis of Variance for a Relationship Between Zygosity (MZ-DC vs. DZ), Number of Placentas (1 vs. 2) and Selected Dependent Variables (Absolute Magnitude of Intrapair Differences in Standardized Somatic Traits)

\begin{tabular}{lllll}
\hline Dependent variables & $F$ & $d f_{1}$ & $d f_{2}$ & $p$ \\
\hline Body weight & 17.12 & 3 & 980 & .00 \\
Total body length & 18.50 & 3 & 980 & .00 \\
Crown-rump length & 17.54 & 3 & 976 & .00 \\
Head circumference & 16.35 & 3 & 980 & .00 \\
Chest circumference & 22.70 & 3 & 980 & .00 \\
\hline
\end{tabular}

Note: $p$ values are significant at $p \leq .05$.

4 , as well as between group 2 and groups 3 and 4 (Table 10). The LSD test confirmed that the number of placentas did not exert significant effect on the magnitude of intrapair differences in the analyzed somatic traits of twins.

\section{Discussion}

One of the methods to determine the share of genetic and environmental factors in the phenotypic variability of anthropometric studies is twin studies. However, the twins need to develop under the same intrauterine environmental conditions if the analysis of intrapair differences in their somatic traits is used for this purpose. Published studies analyzing the role of fetal membrane type as a determinant of intrapair variance in the somatic traits of $M Z$ and DZ twins are sparse, at least when the research on an appropriately selected clinical material is concerned (Silventoinen et al., 2015). Furthermore, the results of the few published studies dealing with the problem in question are inconclusive.

Marceau et al. (2016) in their last article reviewed the literature on chorionicity in twin pregnancies in reference

\section{TABLE 10}

Significance of Differences in the Magnitude of Intrapair Discordance in Standardized Somatic Traits in the Subsets of Twins Differing in Terms of Their Zygosity (MZ- DC vs. DZ) and Placental Number (1 vs. 2)

\begin{tabular}{|c|c|c|c|c|}
\hline Body weight & MZ DC 1p & MZ DC $2 p$ & DZ 1p & DZ 2p \\
\hline MZ DC 1p & & - & $* *$ & $* *$ \\
\hline MZ DC $2 p$ & - & & ** & $* *$ \\
\hline DZ 1p & ** & $* *$ & & - \\
\hline DZ 2p & $* *$ & $* *$ & - & \\
\hline Total body length & MZ DC 1p & MZ DC $2 p$ & DZ 1p & DZ 2p \\
\hline MZ DC 1p & & - & $* *$ & $* *$ \\
\hline MZ DC $2 p$ & - & & $* *$ & $* *$ \\
\hline DZ 1p & ** & $* *$ & & - \\
\hline$D Z 2 p$ & $* *$ & $* *$ & - & \\
\hline Crown-rump length & MZ DC 1p & MZ DC 2p & DZ 1p & DZ 2p \\
\hline MZ DC 1p & & - & $* *$ & $* *$ \\
\hline MZ DC $2 p$ & - & & $* *$ & $* *$ \\
\hline DZ 1p & $* *$ & ** & & - \\
\hline DZ 2p & $* *$ & ** & - & \\
\hline Head circumference & MZ DC 1p & MZ DC 2p & DZ 1p & DZ 2p \\
\hline MZ DC 1p & & - & $* *$ & $* *$ \\
\hline MZ DC 2p & - & & $* *$ & $* *$ \\
\hline DZ 1p & ** & ** & & - \\
\hline DZ 2p & $* *$ & $* *$ & - & \\
\hline $\begin{array}{l}\text { Chest circumference } \\
\text { MZ DC } 1 p\end{array}$ & $M Z D C 1 p$ & MZ DC 2p & $\begin{array}{l}\text { DZ 1p } \\
* *\end{array}$ & $\begin{array}{l}\mathrm{DZ} 2 \mathrm{p} \\
* *\end{array}$ \\
\hline MZ DC $2 p$ & - & & $* *$ & $* *$ \\
\hline DZ 1p & $* *$ & ** & & - \\
\hline DZ 2p & ** & ** & - & \\
\hline
\end{tabular}

to a number of the resulting traits in humans and formulated the following question: To what extent do the differences in chorions in identical twins affect the process of estimating the heredity? In summary, Marceau et al. (2016) found that concerns about estimating the heritability based on the classic twin design, which is founded on the assumption of an identical environment, are not justified given the prenatal environment. However, many authors consistently 
believe that the estimates of heritability are underestimated as for the birth weight, when chorionicity is not taken into account.

According to Race et al. (2006), chorion type is an important variable that may influence prenatal environment of MZ twin pairs, contributing to potential intrapair differences in growth and development. The aim of the study conducted within the pairs of $\mathrm{MZ}$ twins with known chorion type was to verify whether MC twin pairs show more birth-weight discordance than DC twin pairs due to greater intrapair differences in their intrauterine environment. As a result of the studies, it was stated that large discrepancies in birth weight more often occur in MC twin pairs than in DC twin pairs.

Research on the effects of chorionicity on a wide range of phenotypes that resulted in view of a greater similarity of DC-MZ twins than MC-MZ twins has been conducted by different authors (Fagard et al., 2003; Gutknecht et al., 1999; Hur, 2007, Hur \& Shin, 2008; Jacobs et al., 2001; Loos et al., 2005; Race et al., 2006; Reed et al., 2002; Sokol et al., 1995); however, they were most often characterized by small sample sizes and heterogeneity with respect to the age of the twins.

Fick et al. (2006) found 20\% birth-weight discordance in their prospective study of a MC twin cohort from northern California. Since TTTS has been diagnosed in $8 \%$ of twin pairs from the birthweight-discordant subset, the authors pointed to unequal placental sharing as a significant risk factor for birth-weight discordance in diamniotic MC twins. Similarly, Chang (2008), Cleary-Goldman and D’Alton (2008), and Nikkels et al. (2008) perceived an uneven placenta distribution as one of the main causes of noncompliance in fetal growth in MZ twins. Also, according to De Paepe et al. (2010), uneven placental sharing and velamentous cord insertion are two major placental determinants of selective birth-weight discordance in diamniotic MC twins. In turn, the research by Melmed et al. (2012) emphasizes the important role of shared placenta in MC twins as an endocrine organ that leads to greater similarities in MC twins than in DC twins.

The results of a recent Dutch study, which included a group of more than 9,000 twin pairs, imply that intrauterine environment, measured by chorion status, has limited contribution to the similarities in physical and behavioral development of MZ twins. This conclusion was formulated on the basis of a comparative analysis of intrapair differences in 66 traits of MC and DC twins (van Beijsterveldt et al., 2016). Van Beijsterveldt et al. stated that 'the impact of the intrauterine environment on foetal correlation between $\mathrm{MZ}$ twins measured by separating the type of the chorion is small and limited to only few phenotypes' (p. 311). The results of the studies by Mukherjee et al. (2009) also showed no effect of chorionicity on intrapair differentiation for head circumference in newborns from MC and DC twin pregnancies.
Sebire et al. (1998) analyzed $123 \mathrm{MC}$ and $416 \mathrm{DC}$ twin pregnancies and found no significant intrapair differences in fetal size at birth. However, they stated that this observation might have been biased due to the small sample size, and postulated further research on a larger material.

The results of our present study, involving a representative sample of 1,263 twin pairs, provide the basis for unbiased conclusions about the participation of genetic and environmental factors in phenotypic variability of the anthropometric traits.

MZ twins from MC pregnancies complicated by TTTS showed the largest intrapair differences in all analyzed traits, especially body weight and circumference of the chest. These differences resulted from growth discordance associated with one-way transfer of the blood from one fetus to another via arteriovenous anastomoses developed during the course of chronic TTTS (Dias et al., 2010; Rossi \& Prefumo, 2013; Zhao et al., 2016). According to Malinowski and Ropacka (2003), one characteristic feature of this syndrome is considerable intrapair discordance in fetal weights, chest and abdominal circumferences.

Our research shows that the intrauterine environment factor differentiating somatic features of twins is not the number of chorions but the TTTS syndrome. MZ twins from MC pregnancies without TTTS did not differ significantly in intrapair differences in observed characteristics from the MZ twins from DC pregnancies. The advantage of these studies in affecting the reliability of the results is the large number of carefully and clinically selected research material. The lack of clinically documented knowledge about the presence of the TTTS is very often the reason why some claim that the intrauterine environment differentiates the MC twins.

In conclusion, our analysis showed that DZ twins and MZ twins from MC or DC pregnancies without TTTS develop under comparable intrauterine conditions and therefore can be used as a model to study the contribution of genetic and environmental factors to phenotypic variance. The intrauterine environment contributes to intrapair discordance solely in the case of MZ twins from MC pregnancies complicated with TTTS (i.e., approximately $10-20 \%$ of all MZ twins), and this effect is usually stronger than in DZ twins. In turn, the intrauterine environment does not modulate the magnitude of intrapair differences in the somatic traits of MZ twins from MC pregnancies without TTTS and $\mathrm{MZ}$ twins from DC pregnancies.

\section{Acknowledgments}

This work was supported from the statutory funds of the University School of Physical Education in Poznan.

\section{Disclosure of Interests}

None. 


\section{Details of Ethical Approval}

The authors assert that all procedures contributing to this work comply with the ethical standards of the relevant national and institutional committees on human experimentation and with the Helsinki Declaration of 1975, as revised in 2008.

\section{References}

Baldwin, J. V. (1994). Pathology of multiple pregnancy. New York: Springer.

Benirschke, K. (1990). The placenta in twin gestation. Clinical Obstetrics and Gynecology, 33, 18-31.

Bergman, P., \& Sawicki, K. (1988). Zarys metody bliźniąt [An outline of twin studies]. Materiały i Prace Antropologiczne, 108, 11-50.

Bermudez, C., Becerra, C. H., Bornick, P. W., Allen, M. H., Arroyo, J., \& Quintero, R. A. (2002). Placental types and twin-twin transfusion syndrome. American Journal of $\mathrm{Ob}$ stetrics \& Gynecology, 187, 489-494.

Blickstein, I. (1990). The twin-twin transfusion syndrome. Obstetrics \& Gynecology, 76, 714-722.

Brennan, J. N., Diwan, R. V., Rosen, M. G., \& Bellon, E. M. (1982). Feto-fetal transfusion syndrome: Prenatal ultrasonographic diagnosis. Radiology, 14, 535-536.

Bulmer, M. G. (1970). The biology of twinning in man. Oxford: Clarendon Press.

Chang, Y. L. (2008). Monochorionic twin with selective intrauterine growth restriction. Journal of Medical Ultrasound, 16, 194-201.

Cleary-Goldman, J., \& D’Alton, M. E. (2008). Growth abnormalities and multiple gestations. Seminars in Perinatology, $32,206-212$.

Cordero, L., Franco, A., \& Joy, S. D. (2006). Monochorionic monoamniotic twins: neonatal outcome. Journal of Perinatology, 26, 170-175.

Cordero, L., Franco, A., Joy, S. D., \& O’Shaughnessy, R. W. (2005). Monochorionic diamniotic infants without twinto-twin transfusion syndrome. Journal of Perinatology, 25, 753-758.

De Paepe, M. E. (2015). Examination of the twin placenta. Seminars in Perinatology, 39, 27-35.

De Paepe, M. E., Shapiro, S., Young, L., \& Luks, F. I. (2010). Placental characteristics of selective birth weight discordance in diamniotic-monochorionic twin gestations. Placenta, 31, 380-386.

Dias, T., Mahsud-Dornan, S., Bhide, A., Papageorghiou, A. T., \& Thilaganathan, B. (2010). Cord entanglement and perinatal outcome in monoamniotic twin pregnancies. Ultrasound in Obstetrics \& Gynecology, 35, 201-204.

Fagard, R. H., Loos, R. J., Beunen, G., Derom, C., \& Vlietinck, R. (2003). Influence of chorionicity on the heritability estimates of blood pressure: A study in twins. Journal of Hypertension, 21, 1313-1318.

Fick, A. L., Feldstein, V. A., Norton, M. E., Wassel Fyr, C., Caughey, A. B., \& Machin, G. A. (2006). Unequal placen- tal sharing and birth weight discordance in monochorionic diamniotic twins. American Journal of Obstetrics \& Gynecology, 195, 178-183.

Foley, D. L., Neale, M. C., \& Kendler, K. S. (2000). Does intrauterine growth discordance predict differential risk for adult psychiatric disorder in a population-based sample of monozygotic twins?. Psychiatric Genetics, 10, 1-8.

Gielen, M., Lindsey, P. J., Derom, C., Smeets, H. J., Souren, N. Y., Paulussen, A., , ... Nijhuis, J. G. (2008). Modeling genetic and environmental factors to increase heritability and ease the identification of candidate genes for birth weight: A twin study. Behavior Genetics, 38, 44-54.

Gutknecht, L., Spitz, E., \& Carlier, M. (1999). Long-term effect of placental type on anthropometrical and psychological traits among monozygotic twins: A follow up study. Twin Research, 2, 212-217.

Hack, K. E., Derks, J. B., Elias, S. G., Franx, A., Roos, E. J., Voerman, S. K., ... Visser, G. H. (2008). Increased perinatal mortality and morbidity in monochorionic versus dichorionic twin pregnancies: Clinical implications of a large Dutch cohort study. BJOG: An International Journal of $\mathrm{Ob}$ stetrics \& Gynaecology, 115, 58-67.

Haverkamp, F., Lex, C., Hanisch, C., Fahnenstich, H., \& Zerres, K. (2001). Neurodevelopmental risks in twin-to-twin transfusion syndrome: Preliminary findings. European Journal of Paediatric Neurology, 5, 21-27.

Hur, Y. M. (2007). Effects of the chorion type on prosocial behavior in young South Korean twins. Twin Research and Human Genetics, 10, 773-777.

Hur, Y. M., \& Shin, J. S. (2008). Effects of chorion type on genetic and environmental influences on height, weight, and body mass index in South Korean young twins. Twin Research and Human Genetics, 11, 63-69.

Jacobs, N., Van Gestel, S., Derom, C., Thiery, E., Vernon, P., Derom, R., \& Vlietinck, R. (2001). Heritability estimates of intelligence in twins: Effect of chorion type. Behavior Genetics, 31, 209-217.

Lage, J. M., Vanmarter, L. J., \& Mikhail, E. (1989). Vascular anastomoses in fused, dichorionic twin placentas resulting in twin transfusion syndrome. Placenta, 10, 55-59.

Lewi, L. (2010). Monochorionic diamniotic twin pregnancies pregnancy outcome, risk stratification and lessons learnt from placental examination. Verhandelingen - Koninklijke Academie voor Geneeskunde van België, 72, 5-15.

Loos, R. J., Derom, C., Derom, R., \& Vlietinck, R. (2005). Determinants of birthweight and intrauterine growth in liveborn twins. Paediatric and Perinatal Epidemiology, 1, 1522.

Malinowski, W., \& Ropacka, M. (2003). Twin-to-twin transfusion syndrome. In G. Bręborowicz, W. Malinowski, \& E. Ronin-Walknowska (Eds.), Ciaża wielopłodowa [Multiple pregnancy] (pp. 195-222). Poznan: OWN.

Marceau, K., McMaster, M. T. B., Smith, T. F., Daams, J. G., van Beijsterveldt, C. E. M., Boomsma, D. I., \& Knopik, V. S. (2016). The prenatal environment in twin studies: A review on chorionicity. Behavior Genetics, 46, 286-303.

Martin, R. (1988). Anthropologie. Handbuch der vergleichenden biologie des menchen [Anthropology. Textbook of 
human comparative biology]. Stuttgart/NewYork: Gustav Fischer Verlag.

Melmed, S., Polonsky, K. S., Larsen, P. R., \& Kronenberg, H. M. (2012). Williams textbook of endocrinology (12th ed.). Philadelphia: Saunders.

Mukherjee, N., Kang, C., Wolfe, H. M., Hertzberg, B. S., Smith, J. K., Lin, W., ... Gilmore, J.H. (2009). Discordance of prenatal and neonatal brain development in twins. Early Human Development, 85, 171-175.

Nikkels, P. G., Hack, K. E., \& van Gemert, M. J. (2008). Pathology of twin placentas with special attention to monochorionic twin placentas. Journal of Clinical Pathology, 61, 12471253.

Race, J. P., Townsend, G. C., \& Hughes, T. E. (2006). Chorion type, birthweight discordance and tooth-size variability in Australian monozygotic twins. Twin Research and Human Genetics, 9, 285-291.

Reed, T., Pfefferbaum, A., Sullivan, E. V., \& Carmelli, D. (2002). Influences of chorion type on measurements of the corpus callosum in adult monozygotic male twins?. American Journal of Human Biology, 14, 338-346.

Robertson, E. G., \& Neer, K. J. (1983). Placental injection studies in twin gestation. American Journal of Obstetrics \& Gynecology, 147, 170-174.

Ropacka, M. (2003). Diagnostyka ultrasonograficzna ciąży wielopłodowej [Ultrasonographic diagnostics in multiple pregnancy]. In G. Bręborowicz, W. Malinowski, , \& E. Ronin-Walknowska (Eds.), Ciaża wielopłodowa [Multiple pregnancy] (pp. 65-86). Poznan: OWN.

Ropacka, M., Markwitz, W., Keith, L., \& Bręborowicz, G. H. (2001). Treatment and monitoring of twins with fetofetal transfusion. Archives of Perinatal Medicine, 7, 35-40.

Rossi, A. C., \& Prefumo, F. (2013). Impact of cord entanglement on perinatal outcome of monoamniotic twins: A systematic review of the literature. Ultrasound in Obstetrics \& Gynecology, 41, 131-135.

Sebire, N. J., D’Ercole, C., Soares, W., Nayar, R., \& Nicolaides, K. H. (1998). Intertwin disparity in fetal size in monochorionic and dichorionic pregnancies. Obstetrics \& Gynecology, 91, 82-85.

Silventoinen, K., Jelenkovic, A., Sund, R., Honda, C., Aaltonen, S., Yokoyama, Y., ... Kaprio, J. (2015). The CODATwins project: The cohort description of collaborative project of development of anthropometrical measures in twins to study macro-environmental variation in genetic and environmental effects on anthropometric traits. Twin Research and Human Genetics, 18, 348-360.

Sokol, D. K., Moore, C. A., Rose, R. J., Williams, C. J., Reed, T., \& Christian, J. C. (1995). Intrapair differences in personality and cognitive ability among young monozygotic twins distinguished by chorion type. Behavior Genetics, 25, 457466.

Touwslager, R. N. H., Gielen, M., Derom, C., Mulder, A. L. M., Gerver, W. J. M., Zimmermann, L. J., ... Zeegers, M. P. (2011). Determinants of infant growth in four age windows: A twin study. Journal of Pediatrics, 158, 566-572.

van Baal, C. G., \& Boomsma, D. I. (1998). Etiology of individual differences in birth weight of twins as a function of maternal smoking during pregnancy. Twin Research, 1, 123130.

van Beijsterveldt, C. E., Overbeek, L. I., Rozendaal, L., McMaster, M. T., Glasner, T. J., Bartels, M., ... Boomsma, D. I. (2016). Chorionicity and heritability estimates from twin studies: The prenatal environment of twins and their resemblance across a large number of traits. Behavior Genetics, 46, 304-314.

Vlietinck, R., Derom, R., Neale, M. C., Maes, H., van Loon, H., Derom, C., \& Thiery, M. (1989). Genetic and environmental variation in the birth weight of twins. Behavior Genetics, 19, 151-161.

Yinon, Y., Ben Meir, E., Berezowsky, A., Weisz, B., Schiff, E., Mazaki-Tovi, S., \& Lipitz, S. (2014). Circulating angiogenic factors in monochorionic twin pregnancies complicated by twin-to-twin transfusion syndrome and selective intrauterine growth restriction. American Journal of Obstetrics \& Gynecology, 210, 141.

Zanardini, C., Prefumo, F., Fichera, A., Botteri, E., \& Frusca, T. (2014). Fetal cardiac parameters for prediction of twinto-twin transfusion syndrome. Ultrasound in Obstetrics \& Gynecology, 44, 434-440.

Zhao, D., Lipa, M., Wielgos, M., Cohen, D., Middeldorp, J. M., Oepkes, D., \& Lopriore, E. (2016). Comparison between monochorionic and dichorionic placentas with special attention to vascular anastomoses and placental share. Twin Research and Human Genetics, 19, 191-196.

Zhao, D., Slaghekke, F., Middeldorp, J. M., Duan, T., Oepkes, D., \& Lopriore, E. (2014). Placental share and hemoglobin level in relation to birth weight in twin anemia-polycythemia sequence. Placenta, 35, 10701074. 